\title{
PREPARATION AND CHARACTERIZATION OF DRY PRESSED CERAMIC TILES INCORPORATING CERAMIC SLUDGE WASTE
}

\author{
${ }^{\#}$ SH.K. AMIN*, M.G. ELMAHGARY**, M.F. ABADIR*** \\ *Chemical Engineering and Pilot Plant Department, National Research Centre, Dokki, Giza, Egypt \\ **Chemical Engineering Department, Faculty of Engineering, British University, Cairo, Egypt \\ ***Chemical Engineering Department, Faculty of Engineering, Cairo University, Giza, Egypt \\ \#E-mail: dr.shereenkamel@hotmail.com, sheren51078@yahoo.com
}

Submitted July 13, 2018; accepted September 17, 2018

\begin{abstract}
Keywords: Ceramic sludge, Wall tiles, Floor tiles, Recycling
Waste sludge, which is the sediment of washed down particles from ceramic manufacturing processes, constitutes about $2 \%$ by weight of the final products. This sludge consists of a water suspension of coarse particles (feldspar, quartz and ground fired tiles), fine particles (clay minerals such as kaolinite) and glaze waste. Common practice is to filter off this sludge and dump it or to use it in wet grinding of raw materials. In this work, it was re-used in the production of wall and floor tiles. Dried and ground sludge waste was added in percentages from $5 \%$ up to $50 \%$ to standard wall and floor tile mixes, molded and uniaxially pressed at $30 \mathrm{MPa}$, dried then fired at temperatures reaching $1180{ }^{\circ} \mathrm{C}$ for floor tiles and $1160{ }^{\circ} \mathrm{C}$ for wall tiles for a soaking time of $15 \mathrm{~min}$. The properties of both green and fired tiles were investigated as function of percent waste added. The vitrification parameters (linear firing shrinkage, water absorption and apparent porosity) as well as mechanical properties were determined and compared with ISO standards. Samples of tiles having the composition of the proposed mixtures were fired in an industrial roller kiln and their properties determined. The microstructure of some fired sample was investigated by scanning electron microscopy (SEM). It was possible to obtain tiles that abided by ISO standards for sludge addition up to $20 \%$ for floor tiles and up to $10 \%$ for wall tiles.
\end{abstract}

\section{INTRODUCTION}

Ceramic tiles are important construction materials used in almost all buildings. As a manufacturing segment, it has shown a significant growth in production worldwide. The potential seems great, especially as housing, retail, IT and BPO sectors have seen an unprecedented boom in recent years. The main product segments are those of wall tiles, floor tiles, vitrified tiles, and glazed "porcelain" tiles [1].

Huge amount of ceramic waste is produced in ceramic tiles production at different stages such as grinding, blending, drying and glazing posing moderate to severe environmental problems [2]. Natural resources facing a decline with time due to abundant uses, progress in ceramic technology may be a useful way to reduce the use of these natural resources by recycling the ceramic waste coming out from its industries [3]. Recycling and reuse of waste materials will lead to energy saving, cost reduction, possibly superior products and little or no hazards to the surrounding environment.

The reuse of diverse waste types in the ceramic tiles industry has been researched by many workers. Most authors have directed their research towards the reuse of waste ceramic tiles in concrete making [4-6].

On the other hand the reuse of waste within the tile factory was not widely researched. In this respect,
Manfredini et al. [7] have considered a way of minimizing the pollution due to ceramic sludge by rationalizing the addition of waste waters and sludge in tile production processes. The analytical and rheological results obtained on the body slips used for "white gres" tile production in waste or purified waters revealed that the addition of dried sludge up to $5 \%$ by weight produces a slip totally compatible with industrial requirements. However the extent of this work was limited to the possibility of using the sludge as substitute for water in the wet grinding operation, a practice recommended by the European commission [8]. In this respect, the effect of the extent of addition on tiles properties has not been investigated to date.

More recently, Roushdy et al. [9] have successfully used the fine waste obtained from grinding of rollers of the firing kiln as an addition to wall tiles bodies. They concluded that adding of 1 to $2 \%$ of that waste to a standard wall tiles mix produced products abiding by Standards and helps eliminating a hazardous waste.

The present work discusses the possibility of substituting part of the main body mix of wall or floor ceramic tiles by the sludge produced from waste water treatment unit of a ceramic factory to produce ceramic tiles. Such reuse serves a dual purpose of economically and environmentally managing a factory waste. 


\section{EXPERIMENTAL}

\section{Characterization of the raw materials}

Two main raw materials were used. First, the raw mix used to manufacture ceramic wall and floor tile bodies (Kindly supplied by “Ceramica Venus Company" located in the $10^{\text {th }}$ of Ramadan City, Egypt), the composition of which is displayed in Table 1. Second, de-watered sludge from the water treatment unit of the same factory was collected, dried and ground before usage.

The chemical composition of both materials was determined using X-ray fluorescence technique type. The used machine was Axios, panalytical 2005, wave length dispersive (WD-XRF) sequential spectrometer.

On the other hand, the mineralogical composition was assessed using X-ray diffraction Brukur D8 advanced computerized X-ray diffractometer apparatus with mono chromatic $\mathrm{Cu} \mathrm{K} \alpha$ radiation, operated at $40 \mathrm{kV}$ and $40 \mathrm{~mA}$.

The particle size distribution was determined according to the standard sieving procedure described by ASTM D 422 [10].

Finally, the powder densities of tiles raw mix and sludge waste were measured using the standard Pycnometer method (density flask) [11, 12].

\section{Preparation and testing of the samples}

The preparation of different tile specimens and subsequent testing was carried out as follows:

- The recovered dried sludge waste was ground using a laboratory ball mill of $0.5 \mathrm{~kg}$ capacity using alumina balls. The fine powder was then used to replace part of the basic mixture for wall and floor tiles in percentage of weight varying from 0 to $50 \%$ by $10 \%$ steps.

- Water was then added to the different samples with a percentage of $5-7 \%$ by weight. The plasticity of the different blends was determined using the Pfefferkorn method [12].

- Tile specimens of approximate dimensions of $111 \times$ $\times 55 \times 7 \mathrm{~mm}^{3}$ were prepared from the blends by dry pressing using a laboratory hydraulic press under a uniaxial pressure of $30 \mathrm{MPa}$. Tile specimens were dried in a laboratory dryer for 8 hours at $145{ }^{\circ} \mathrm{C}$. Linear drying shrinkage and dry modulus of rupture were then determined for the dried samples. Each sample consisted of three specimens and the average value was calculated.
- Specimens were then fired in a laboratory muffle furnace following a programmed schedule that takes into account the evolution water from the dehydroxylation of kaolinite by fixing the temperature at $750{ }^{\circ} \mathrm{C}$ for $30 \mathrm{~min}$. The maximum temperatures attained were $1160{ }^{\circ} \mathrm{C}$ for wall tiles and $1180{ }^{\circ} \mathrm{C}$ for floor tiles with a soaking time of $15 \mathrm{~min}$ to simulate fast firing conditions.

- The following tests were performed to determine the characteristics of fired samples: Percent linear firing shrinkage [14], percent water absorption and apparent porosity [15], breaking strength and modulus of rupture [16]. SEM was also used to provide micrographs of some chosen sections. The used SEM apparatus was of type JEOL-JSM 6510 apparatus with maximum zoom magnification power $=300,000 \times$.

\section{Quality assessment of the samples}

The recommended compositions were subsequently shaped in a modular tile form of $200 \times 200 \mathrm{~mm}^{2}$ with a thickness of $9 \mathrm{~mm}$. Seven tile specimens were dry pressed at $35 \mathrm{MPa}$, dried, engobed, glazed, then fired in a production line of the factory through a single fast firing technique, using an industrial roller kiln, where the maximum firing temperature was about $1160{ }^{\circ} \mathrm{C}$ for wall tiles, and $1180^{\circ} \mathrm{C}$ for floor tiles with a soaking time of $15 \mathrm{~min}$. The total firing cycle did not exceed 45 minutes. The glazed tile specimens were examined for conformity to both international and internationally harmonized Egyptian standards of dry pressed ceramic tiles $[17,18]$ for the purpose of quality assessment.

\section{RESULTS AND DISCUSSIONS}

\section{Raw materials characterization Chemical analysis}

The chemical analyses of sludge waste, wall tile mix, and floor tile mix are shown in Table 2. The loss on ignition is higher for wall tile mix than for floor tile since the former contains limestone while most of the LOI of the latter is due to dehydroxylation of clays. On the other hand, the organic matter content of the three aforementioned materials was found to be $2.96 \%$, $1.35 \%$, and $1.05 \%$ respectively.

Table 1. Raw mix tiles body composition.

\begin{tabular}{lccccccccc}
\hline Percent & $\begin{array}{c}\text { Aswan } \\
\text { clay }\end{array}$ & $\begin{array}{c}\text { Kaolin } \\
\text { clay }\end{array}$ & $\begin{array}{c}\text { Ball } \\
\text { clay }\end{array}$ & Bentonite & Feldspars & Sand & $\begin{array}{c}\text { Green tiles } \\
\text { scrap }\end{array}$ & Limestone & Talc \\
\hline Wall tile mix & 36 & 9 & 10 & 1.5 & 25 & 9.5 & - & 9 & - \\
Floor tile mix & 22 & 1 & 19 & 2 & 40.5 & 5.5 & 7 & - & 3 \\
\hline
\end{tabular}


Table 2. Chemical analysis of raw materials.

\begin{tabular}{|c|c|c|c|}
\hline $\begin{array}{l}\text { Main } \\
\text { constituents }\end{array}$ & $\begin{array}{c}\text { Sludge waste } \\
(\%)\end{array}$ & $\begin{array}{l}\text { Wall mix } \\
(\%)\end{array}$ & $\begin{array}{l}\text { Floor mix } \\
(\%)\end{array}$ \\
\hline $\mathrm{SiO}_{2}$ & 67.38 & 55.51 & 61.21 \\
\hline $\mathrm{TiO}_{2}$ & 0.65 & 0.91 & 0.83 \\
\hline $\mathrm{AlO}_{3}$ & 15.35 & 19.73 & 20.19 \\
\hline $\mathrm{Fe}_{2} \mathrm{O}_{3}^{\text {tot. }}$ & 4.25 & 5.10 & 4.78 \\
\hline $\mathrm{MgO}$ & 0.79 & 0.40 & 0.99 \\
\hline $\mathrm{CaO}$ & 2.57 & 5.15 & 1.21 \\
\hline $\mathrm{Na}_{2} \mathrm{O}$ & 2.75 & 1.43 & 2.72 \\
\hline $\mathrm{K}_{2} \mathrm{O}$ & 1.43 & 1.17 & 1.21 \\
\hline $\mathrm{P}_{2} \mathrm{O}_{5}$ & 0.19 & 0.23 & 0.21 \\
\hline $\mathrm{SO} 3$ & 0.14 & 0.31 & 0.28 \\
\hline $\mathrm{Cl}$ & 0.03 & 0.09 & 0.10 \\
\hline Minor oxides & 0.276 & 0.284 & 0.286 \\
\hline L.O.I & 4.18 & 9.68 & 5.99 \\
\hline TOTAL & 99.986 & 99.994 & 100.006 \\
\hline
\end{tabular}

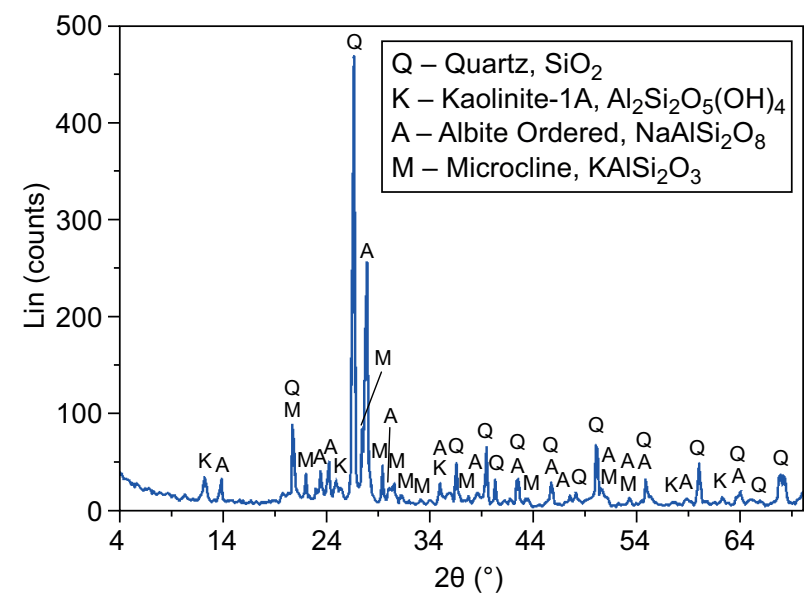

a) sludge waste

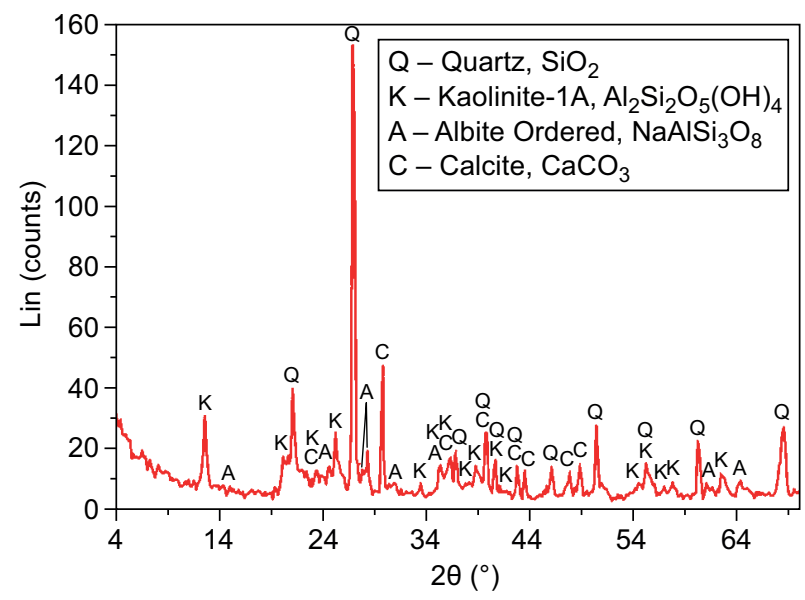

b) wall mix

\section{Mineralogical analysis}

The XRD patterns of all raw materials are revealed in Figure 1. As expected, waste sludge is composed of a mixture of all ingredients constituting the raw mixes for wall and floor tiles, namely, kaolinite $\left(\mathrm{Al}_{2} \mathrm{O}_{3} \cdot 2 \mathrm{SiO}_{2} \cdot 2 \mathrm{H}_{2} \mathrm{O}\right)$, quartz, microcline $\left(\mathrm{K}_{2} \mathrm{O} \cdot \mathrm{Al}_{2} \mathrm{O}_{3} \cdot 6 \mathrm{SiO}_{2}\right)$ and albite $\left(\mathrm{Na}_{2} \mathrm{O} \cdot \mathrm{Al}_{2} \mathrm{O}_{3} \cdot 6 \mathrm{SiO}_{2}\right)$.

On the other hand, both wall and floor tiles mixes are composed of quartz, kaolinite, and albite. Wall tiles XRD further exhibits lines of calcite $\left(\mathrm{CaCO}_{3}\right)$ while these do not appear on the XRD pattern of floor tiles due to their limited percentage.

\section{Screen analysis}

Figure 2 shows both of the cumulative and differential screen analysis of ceramic sludge waste, floor, and wall mixes, which were determined using a set of standard sieves according to ASTM D 422 [9].

Figure $2 \mathrm{a}$ shows the cumulative screen analysis of raw materials. The vertical axis represents the fraction retained on each particular screen diameter. From this Figure, the mean particle size of sludge waste is much lower than that of either wall or floor tiles mix. This elevated level of fineness is due to the incorporation of more clay powder waste in the sludge owing to its dusty character that causes its material loss to be higher than that of other species.

Also, the bimodal distribution of particle size of both tile mixes in Figure $2 b$ is presumably due to the presence of relatively large amounts of free silica in both mixes. This is since the grindability of silica is much lower than that of clays leaving larger particles in the ground product compared to clay particles. On the other hand, the lower "intensity" peak of sludge points out to a lesser level of free silica which is in accordance with the expected higher amount of clay waste present in that waste.

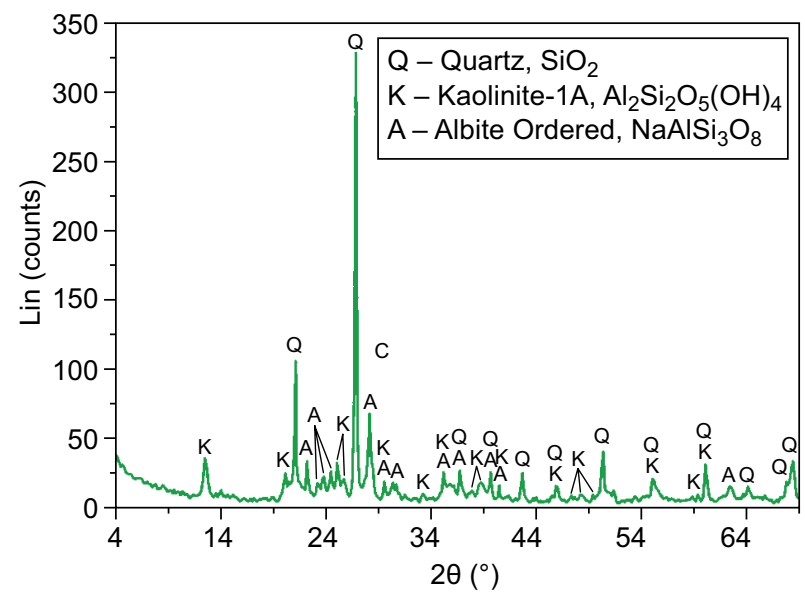

c) floor mix

Figure 1. XRD patterns of the used raw materials: a) sludge waste, b) wall mix, and c) floor mix. 


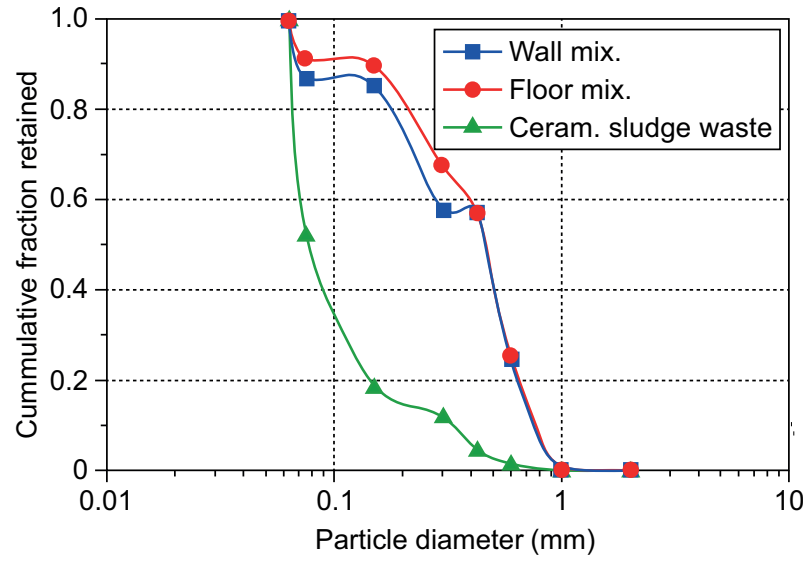

a) cumulative analysis

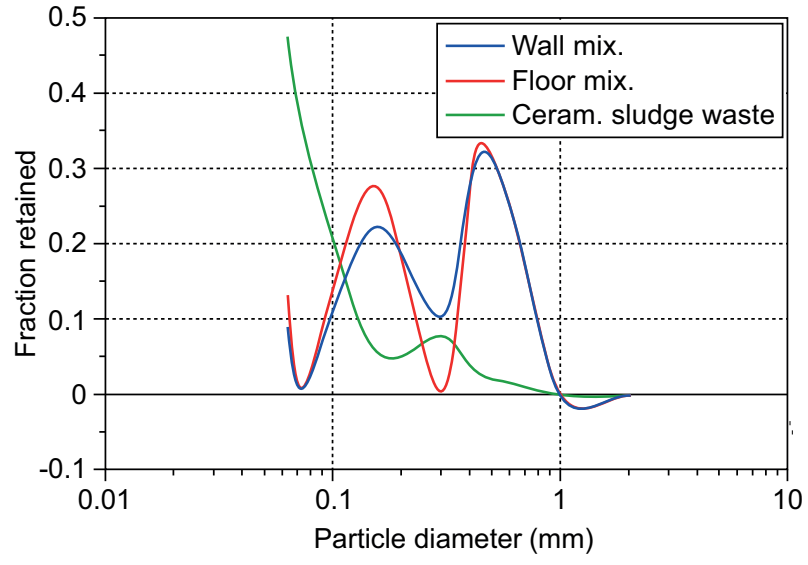

b) differential analysis

Figure 2. Particle size distribution of the raw materials, (a) cumulative analysis, and (b) differential analysis.

Several methods have been devised to obtain a good estimate of the mean particle size. Probably, the most used is the volume - surface mean diameter $\left(\bar{D}_{s}\right)$, which is related to the specific surface area $\left(A_{w}\right)$. It is defined by the following equation [19]:

$$
\bar{D}_{v s}=\frac{1}{\sum_{i=1}^{n} \cdot X_{i} / D_{P l}}
$$

where: $X i$ is the differential fraction retained between two sieves $(i)$ and $(i-1), \bar{D}_{v s}$ is the average particle diameter, or the mean nominal screen opening between these two sieves.

Table 3 shows the values of both of the volume surface mean diameter $\left(\bar{D}_{v s}\right)$ and the median diameter $\left(D_{50}\right)$ for all powders.

Table 3. Volume - surface mean and median diameter of raw materials.

\begin{tabular}{lccc}
\hline Powder & Sludge waste & Wall mix & Floor mix \\
\hline $\mathrm{D}_{50} \mathrm{~mm}$ & 0.075 & 0.425 & 0.425 \\
$\overline{\mathrm{D}}_{\mathrm{vs}} \mathrm{mm}$ & 0.1 & 0.28 & 0.24 \\
\hline
\end{tabular}

\section{Powder density}

The powder densities of sludge waste, wall tiles mix, and floor tiles mix were found to equal 2.15, 2.60 and $2.49 \mathrm{~g} \cdot \mathrm{cm}^{-3}$, respectively.

\section{Properties of unfired tiles samples \\ Effect of ceramic sludge replacement on the plasticity of mixes}

The Pfefferkorn plasticity was determined for different specimens of wall tiles and floor tiles mixes for up to $50 \%$ substitution of basic mix. Figure 3 illustrates the effect of substitution on plasticity. Both curves display to a different degree a maximum value of plasticity over a certain range of replacement by waste. For wall tiles, this maximum occurs in the range of substitution $10-20 \%$ while the corresponding range for floor tiles mixes is $15-30 \%$. The interpretation of this behavior is linked to the drying shrinkage that will be discussed in the next section.

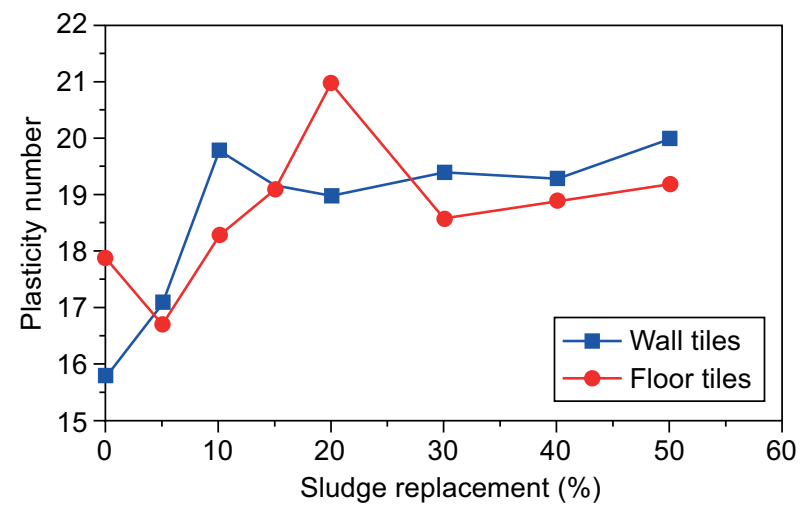

Figure 3. Effect of percent ceramic sludge replacement on plasticity number.

\section{Effect of ceramic sludge replacement on drying shrinkage}

Figure 4 illustrates the effect of sludge addition on the drying linear shrinkage. Both curves show an increase in shrinkage following addition of waste sludge up to about $10 \%$ level, followed by a decrease reaching its minimum value at $30-40 \%$ addition followed by slight increase in shrinkage as the addition reaches $50 \%$.

The reason for such behavior is related to two factors, namely, the elevated level of clays in waste compared to tile mixes and their lower particle size. Upon adding the more plastic waste to the tile mixes, shrinkage expectedly increases up to a certain level of addition. However, as more fine waste is added, its particles start filling in the pores between the coarser tile mix particles decreasing the ability of the body to shrink. 
This is the reason why shrinkage decreases to reach its minimum value at about $30-40 \%$ addition. This percentage corresponds to the maximum compactness of the mix [20]. Any further addition will result in a more loosely packed porous structure allowing once more for shrinkage to increase.

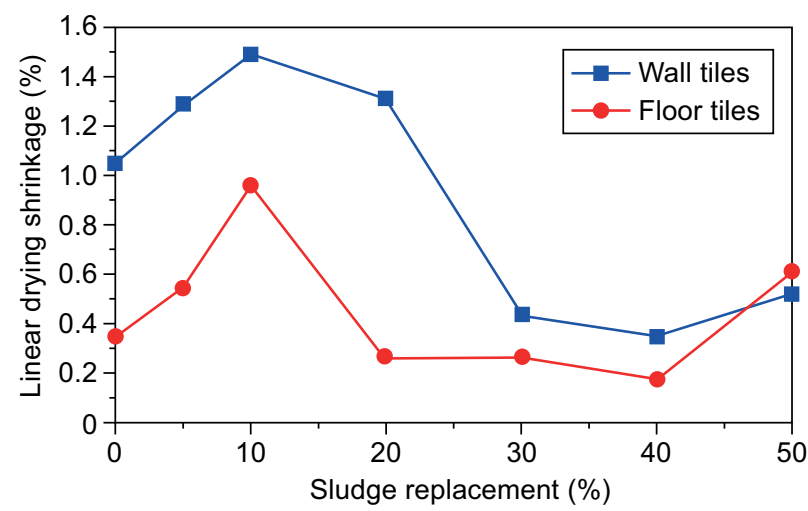

Figure 4. Effect of percent ceramic sludge replacement on linear drying shrinkage.

As more plastic mixes are associated with higher shrinkage, it is to be expected that Figures 3 and 4 will bear some resemblance.

\section{Effect of ceramic sludge replacement on green strength}

Figures 5a, b illustrate the effect of waste addition on green breaking strength and green modulus of rupture (MOR). As can be followed from these figures, the general trend of the curves, particularly in case of wall tiles, is more or less in harmony with the results of drying shrinkage. That is, the higher the shrinkage the higher the green strength. However, this holds true up to $40 \%$ addition since at higher addition levels, fine waste particles segregate from the mix as the pores between the coarse particles get totally filled at about $40 \%$ fine addition.

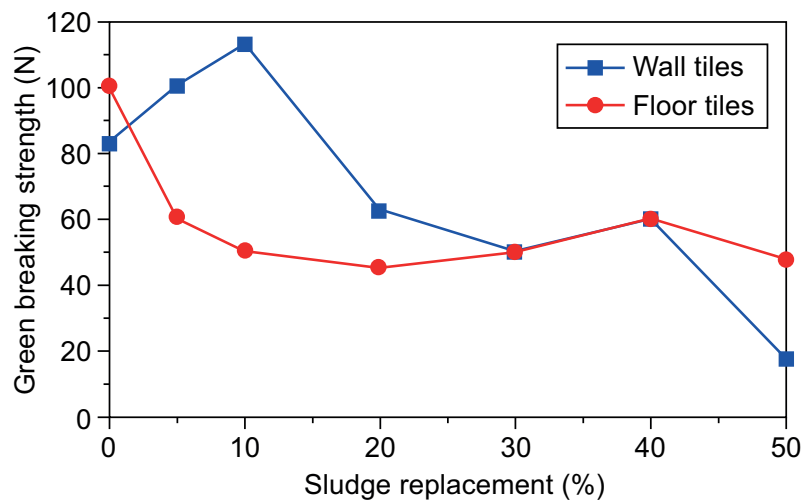

a) green breaking strength
Although the green strength is by no means a standard requirement of ceramic tile, it nevertheless affects the proportion of rejected dry tiles due to losses on handling. There is no recommended figure for green breaking strength (or alternatively, modulus of rupture) although values of MOR higher than $1 \mathrm{MPa}$ are commonly associated with the requirement of minor losses on handling. Figure $5 \mathrm{~b}$ indicates that for all waste addition percentages the MOR is above the recommended value while in case of wall tiles a maximum percent substitution of $30 \%$ should not be exceeded.

\section{Properties of fired tiles samples \\ Effect of ceramic sludge replacement on firing shrinkage}

The linear firing shrinkage of fired ceramic tiles is represented as a function of percent sludge replacement in Figure 6a. For wall tiles mixes, the results indicate that the values of linear firing shrinkage generally fluctuate about a mean value of $1 \%$ with a maximum shrinkage of $2.12 \%$ at zero addition. The minimum value obtained is $0.35 \%$ at $40 \%$ addition once more associated with maximum compactness of the mix.

Regarding floor tiles, the presence of feldspar in large amounts promotes liquid phase sintering which yields values of linear firing shrinkage much higher than in case of wall tile mixes. The addition of waste in which the level of fine clays is elevated on the expense of feldspars will tend to oppose that trend by generally decreasing firing shrinkage. The values of linear firing shrinkage drop from an initial value of $7.1 \%$ to about $4.5 \%$ as the substitution level increases from 0 to $50 \%$.

\section{Effect of ceramic sludge replacement on loss on ignition}

The variation of loss on ignition with varying amounts of waste for both types of tiles is shown in Figure $6 \mathrm{~b}$. In case of wall tiles, an appreciable portion of

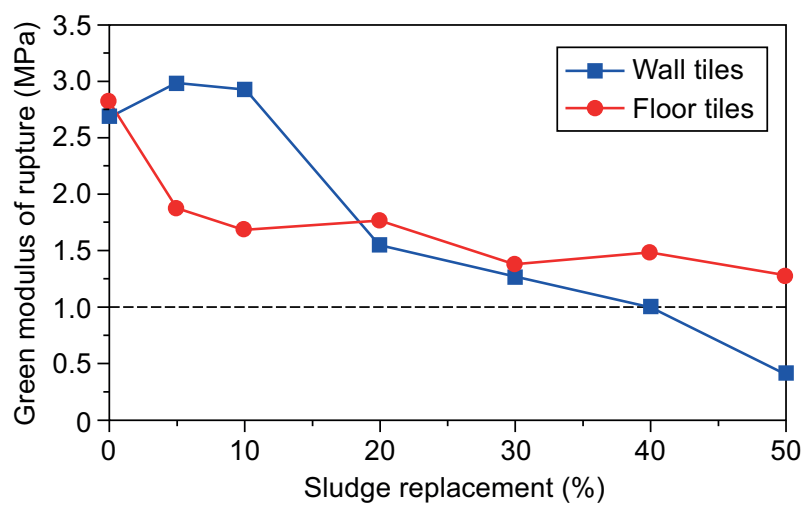

b) green modulus of rupture

Figure 5. Effect of percent ceramic sludge replacement on: a) green breaking strength, and b) green modulus of rupture. 
the LOI is due to the decomposition of limestone present in the original mix. As sludge waste is added, this loss will inevitably decrease because of the low content of calcium carbonate present in this waste compared to that in the wall mix (Table 2).

In case of floor tiles, the decrease in LOI upon adding the waste is much less noticeable due to the low content of calcium carbonate in both floor mix and waste.

\section{Effect of ceramic sludge replacement on water absorption}

Water absorption is a main property to be reckoned with when characterizing ceramic tiles of any type. Its value is related to the open porosity of the tile that reflects the degree of vitrification. According to both International Standard [17] and harmonized Egyptian Standard [18], ceramic tiles are classified as either having percent water absorption higher than $10 \%$ or lying between $(3-6 \%)$ or between (6-10\%). Wall tiles usually lie in the former category although that category is not restricted to wall tiles only. In general, wall tiles with values higher than $20 \%$ should be distinguished when packaged by clearly displaying the percent absorption on the package [17, $18]$.

As can be seen from Figure $6 \mathrm{c}$, the addition of waste steadily increases the percent water absorption in case of wall tile specimens, although that property is usually more affected by the value of firing temperature than that of any waste added. In case of wall tiles the values of percent water absorption exceeded the recommended minimum of $10 \%$. The elevated values of water absorption indicate a lack of proper vitrification that is also responsible for low firing shrinkage.

As expected, in case of floor tiles, water absorption values are markedly less than in case of wall tiles. Floor tiles are usually categorized as having water absorption $<10 \%[17,18]$.

\section{Effect of ceramic sludge replacement on apparent closed, and total porosities and bulk density}

Although the apparent porosity is not a standard requirement, it is indicative of the percent open pores and hence extent of vitrification in more direct way than water absorption, to which it is strongly related.

As expected, in case of wall or floor tiles, the effect of adding waste is an increase in open pores following oxidation of organic components present in waste. The high level of feldspar present in floor tiles recipe enhances vitrification which reflects on lower porosity levels compared to wall tiles fired at the same temperature, as can be followed in Figure $6 \mathrm{~d}$.

Values of total porosity are plotted against percent substitution of waste in Figure 6e. This figure discloses the expected fact that floor tile mixes contain in general much more closed porosity than wall tiles mixes and that addition of sludge waste increases the values of total porosity.

The bulk density will decrease following a decrease in porosity. This is made clear in Figure $6 f$ displaying the effect of waste addition on bulk density in the two types of fired bodies.

Actually, the determination of bulk density allows for determining the amount of closed porosity using its basic definition:

$$
\rho_{B}=\rho_{S}(1-\rho)
$$

where, $p$ is the total fractional porosity $=$ open porosity + + closed porosity.

\section{Effect of ceramic sludge replacement on mechanical properties}

The effect of adding sludge waste to wall and floor tiles mixes on mechanical properties was established as being one of the most important properties governing the viability of using the tiles. In this respect, the breaking strength and the modulus of rupture serve to assess the mechanical strength of the tile body. Other properties such as abrasion resistance and skid resistance are concerned with the finished glazed surface rather than the body are were not consequently considered in this work.

Actually, breaking strength and modulus of rupture are closely related although both International Standard and harmonized Egyptian Standard [17, 18] set specific minimum values for each separately. Table 4 shows the permissible values for tiles with water absorption $3 \%<\mathrm{E}$ $\leq 6 \%, 6 \%<\mathrm{E} \leq 10 \%$, and $\mathrm{E}>10 \%$. In the present case, water absorption of wall tiles lies within the $>10 \%$ range (Figure 6c). This corresponds to a minimum breaking strength of $200 \mathrm{~N}$ and MOR of $15 \mathrm{MPa}$ for tile thickness $<7.5 \mathrm{~mm}$, which is the case in the prepared specimens. As for floor tiles, the targeted water absorption range was 3 - $6 \%$ corresponding to a breaking strength of $600 \mathrm{~N}$ and MOR of $22 \mathrm{MPa}$.

Figure $6 \mathrm{~g}$ reveals the effect of substitution by sludge waste on the breaking strength. It can be seen that for wall tiles, a maximum of $10 \%$ sludge can be substituted for the basic mixture which displayed a breaking strength of $580 \mathrm{~N}$ and a breaking strength of $17.3 \mathrm{MPa}$. On the other

Table 4. ISO and ES Standards limits for breaking strength and MOR of dry pressed ceramic tiles.

\begin{tabular}{|c|c|c|c|c|c|c|}
\hline & \multicolumn{3}{|c|}{ Thickness $<7.5 \mathrm{~mm}$} & \multicolumn{3}{|c|}{ Thickness $\geq 7.5 \mathrm{~mm}$} \\
\hline & $3 \%<\mathrm{E} \leq 6 \%$ & $6 \%<\mathrm{E} \leq 10 \%$ & $\mathrm{E}>10 \%$ & $3 \%<\mathrm{E} \leq 6 \%$ & $6 \%<\mathrm{E} \leq 10 \%$ & $\mathrm{E}>10 \%$ \\
\hline Breaking strength, $\mathrm{N}$ & 600 & 500 & 200 & 1000 & 800 & 600 \\
\hline $\mathrm{MOR}, \mathrm{N} \cdot \mathrm{mm}^{-2}(\mathrm{MPa})$ & 22 & 18 & 15 & 22 & 18 & 12 \\
\hline
\end{tabular}




\section{Preparation and characterization of dry pressed ceramic tiles incorporating ceramic sludge waste}

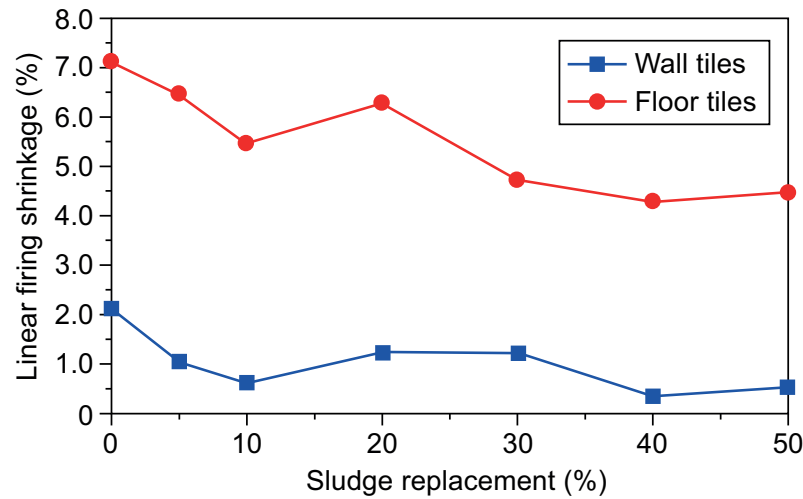

a)

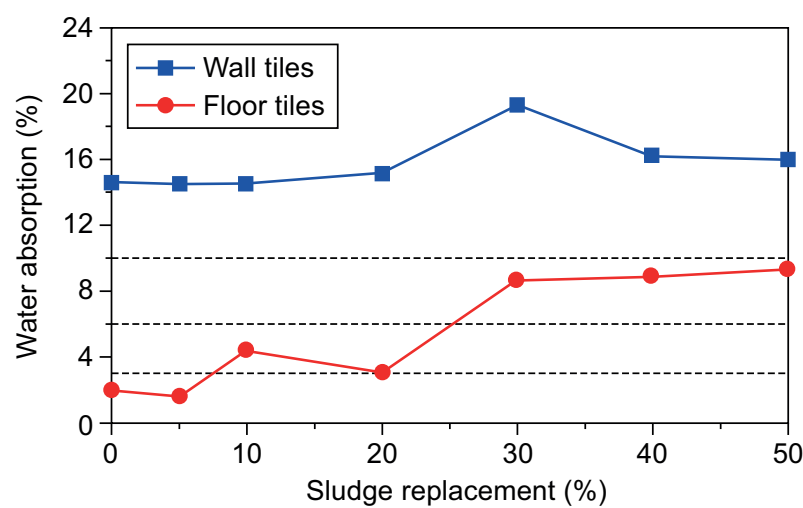

c)

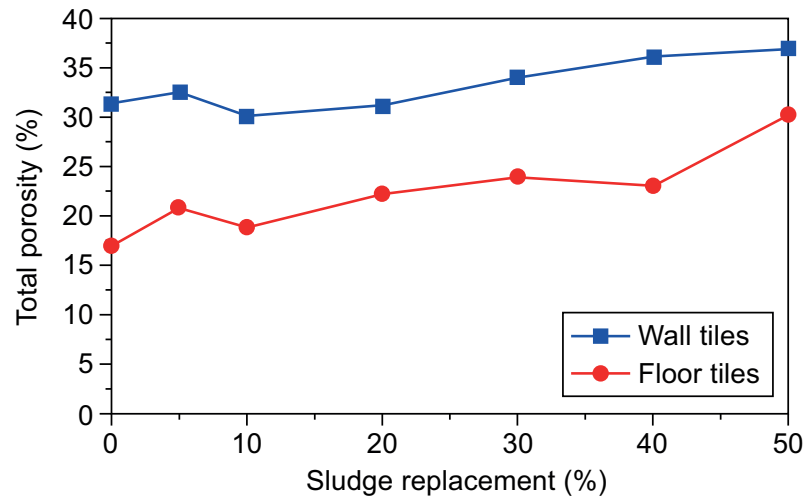

e)

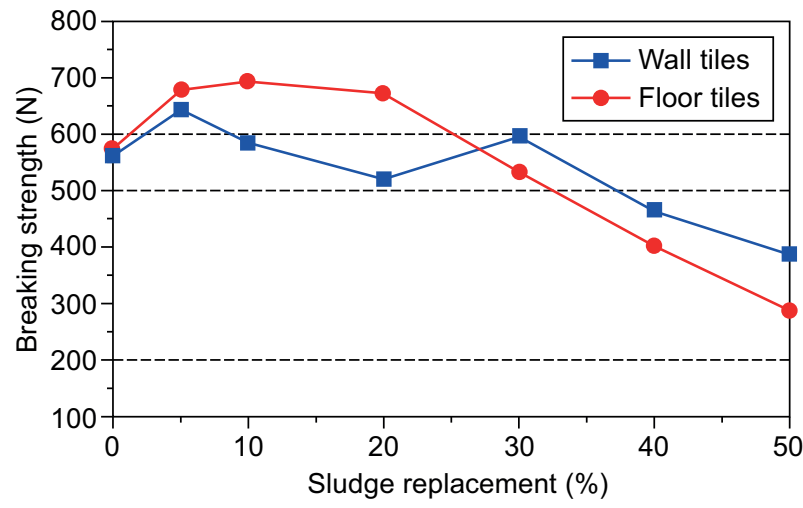

g)

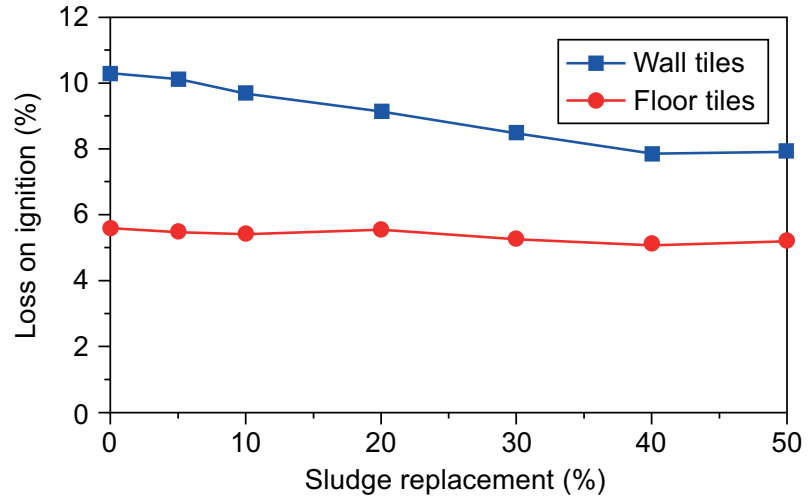

b)

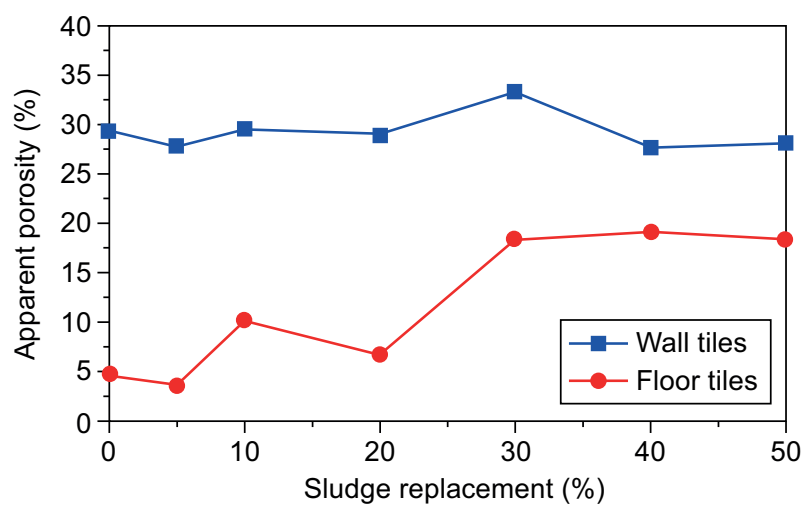

d)

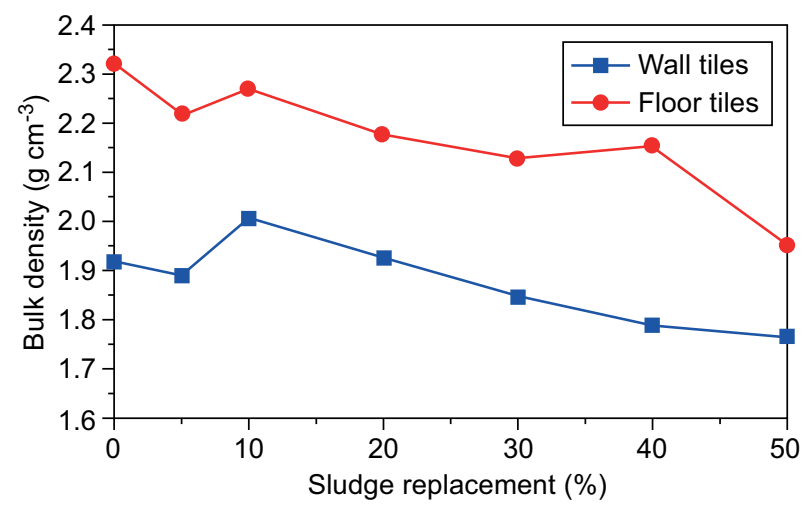

f)

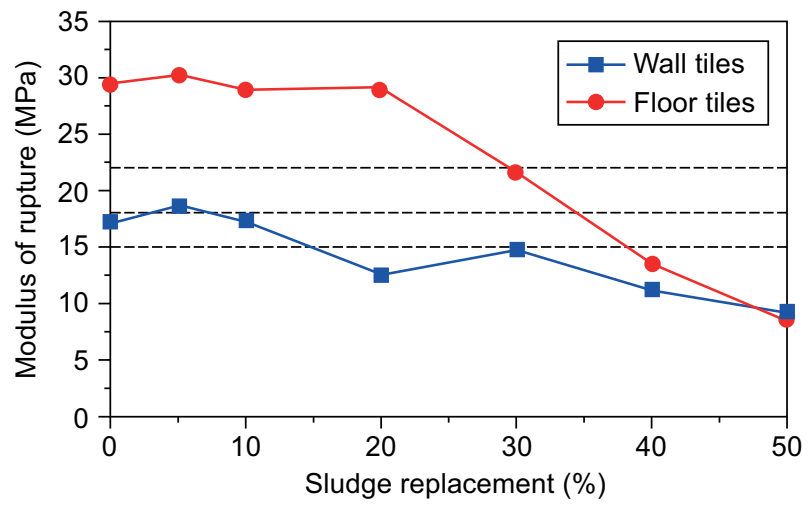

h)

Figure 6. Effect of percent ceramic sludge replacement on properties of fired tiles. 
hand, it is possible to extend the percent substitution in floor tiles to $20 \%$ that displayed values of breaking strength and MOR of $670 \mathrm{~N}$ and $29 \mathrm{MPa}$ respectively.

\section{SEM results for fired samples}

To assess the previously obtained results, specimens were examined under the Scanning Electron Microscope (SEM). Figure 7a represents the microstructure of a wall tile specimen containing $10 \%$ sludge fired at $1160{ }^{\circ} \mathrm{C}$ for 15 minutes $(1000 \times)$ where the presence of pores is apparent. There is also evidence of some liquid phase formation.

On the other hand, Figure $7 \mathrm{~b}$ shows a micrograph of a floor tile mixture containing $20 \%$ sludge fired at $1180{ }^{\circ} \mathrm{C}$ for 15 minutes, while Figure $7 \mathrm{c}$ corresponds to

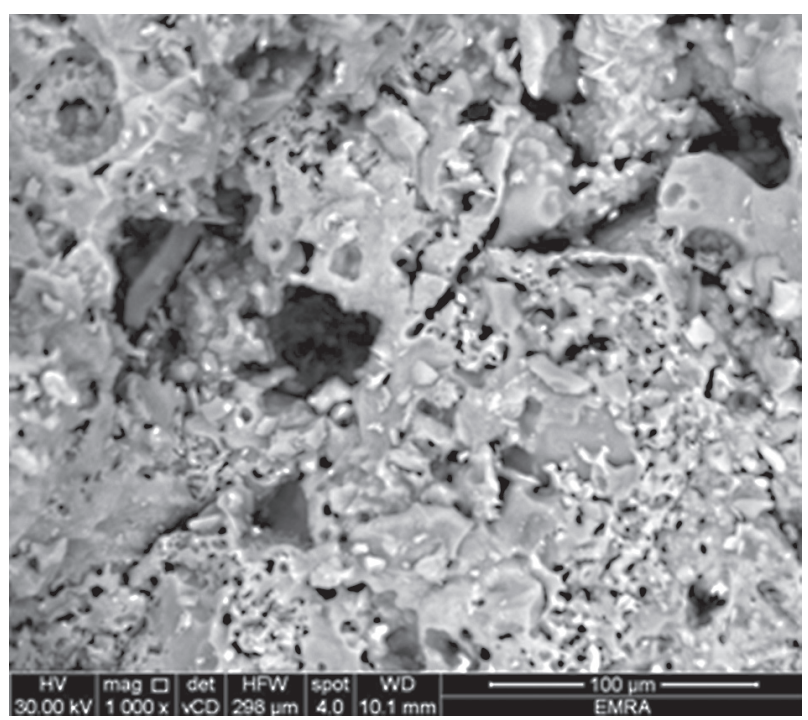

a) wall tile mix containing $10 \%$ sludge

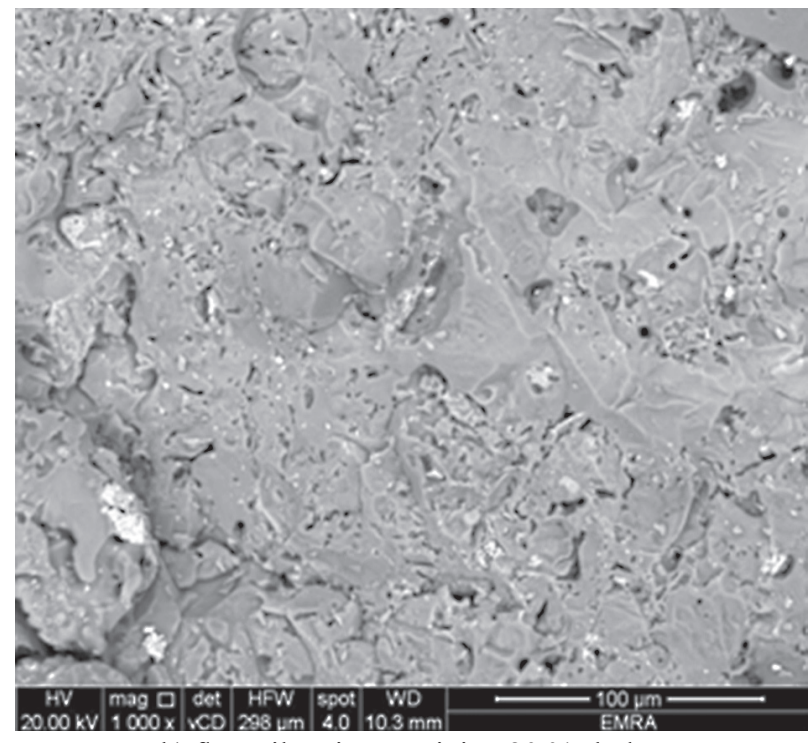

b) floor tile mix containing $20 \%$ sludge a floor tile mixture containing $50 \%$ sludge fired under the same conditions. Both micrographs reveal the presence of appreciable amounts of glassy phase. However, while the former specimen shows little porosity, the latter displays higher level of porosity, an observation compatible with the results obtained for the variation of porosity with sludge addition.

\section{Quality assessment}

Finally, seven fired glazed tile specimens were prepared with dimensions $200 \times 200 \times 9 \mathrm{~mm}^{3}$, in which the raw mix was substituted by ceramic sludge in $10 \%$ and $20 \%$ levels for wall and floor tiles respectively. They were tested for the following properties: percent water absorption, breaking strength, MOR, abrasion resistance, coefficient of friction, crazing resistance, resistance to staining and chemicals according to both International and harmonized Egyptian standards [17, 18].

Table 5 shows the composition of these specimens that have been found to comply with the standards allowable limits for both floor and wall tiles of thickness $>7.5 \mathrm{~mm}$.

\section{CONCLUSIONS}

Dried and ground sludge was mixed with a standard mix of ceramic wall and floor tiles at percentages reaching $50 \%$, molded and pressed uniaxially at $30 \mathrm{MPa}$. Firing was performed for a soaking period of $15 \mathrm{~min}$ to simulate industrial fast firing conditions at $1160{ }^{\circ} \mathrm{C}$ and $1180{ }^{\circ} \mathrm{C}$ for wall and floor tiles samples respectively. It was possible to obtain floor tiles that abided by standards for maximum addition of $20 \%$ sludge (for water absorption;

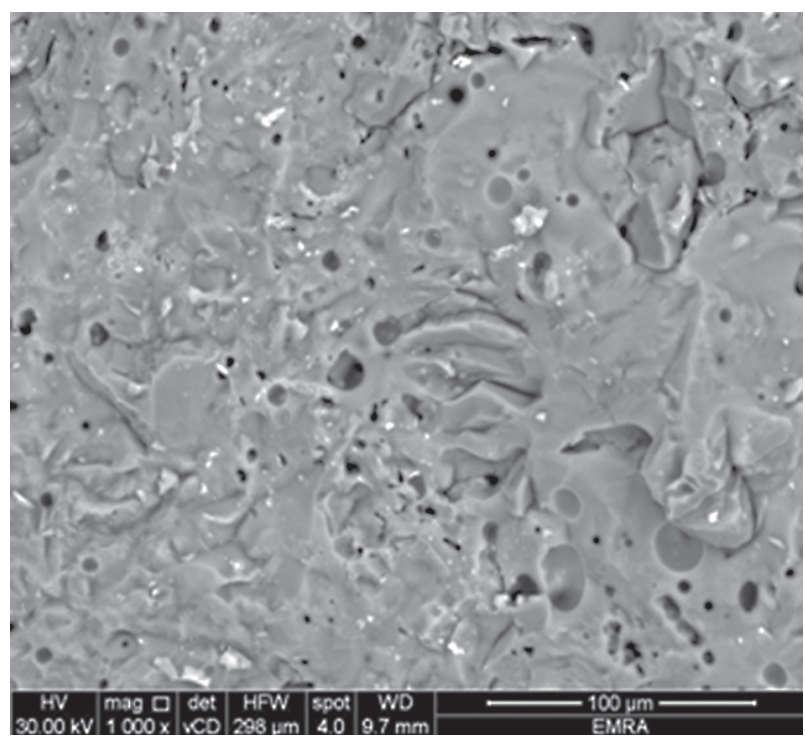

c) floor tile mix containing $50 \%$ sludge

Figure 7. SEM micrographs $(1000 \times)$ for different specimens: a) wall tile mix containing $10 \%$ sludge, b) floor tile mix containing $20 \%$ sludge, and c) floor tile mix containing $50 \%$ sludge. 


\begin{tabular}{|c|c|c|c|c|c|c|}
\hline 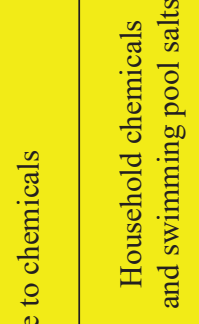 & 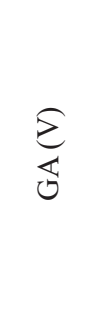 & $\underset{\mho}{\mathbb{E}}$ & $\underset{\mathbb{J}}{\mathcal{E}}$ & $\sum_{\mathbb{J}}^{\mathbb{E}}$ & $\begin{array}{l}\mathcal{E} \\
00 \\
0 \\
\vdots \\
\text { 竞 }\end{array}$ & 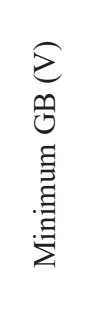 \\
\hline 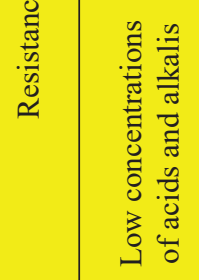 & 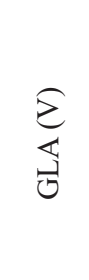 & 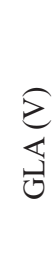 & 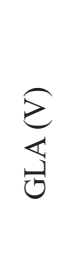 & 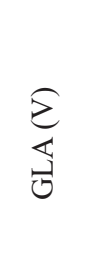 & 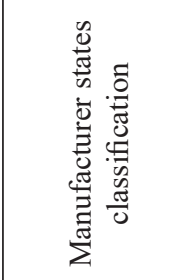 & 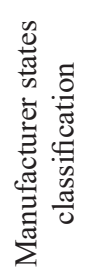 \\
\hline 志 & $\begin{array}{l}\sqrt[\pi]{0} \\
\frac{0}{\pi} \\
0 \\
0\end{array}$ & $\frac{\pi}{\frac{0}{0}}$ & $\begin{array}{l}\frac{\pi}{0} \\
\frac{0}{0} \\
\tilde{\pi} \\
0\end{array}$ & $\frac{\widetilde{c}}{\frac{\pi}{\pi}}$ & 言亮 & 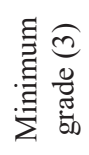 \\
\hline 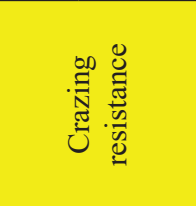 & $\begin{array}{l}\text { w } \\
\text { z } \\
\tilde{a}\end{array}$ & $\begin{array}{c}w \\
\tilde{a} \\
0\end{array}$ & $\begin{array}{c}\mathscr{w} \\
\tilde{\sigma} \\
\tilde{a}\end{array}$ & $\begin{array}{c}w \\
\tilde{a} \\
\tilde{a}\end{array}$ & 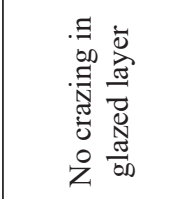 & 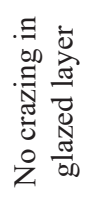 \\
\hline 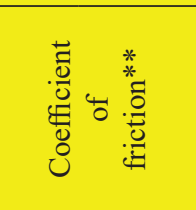 & ? & 1 & 1 & ?3 & 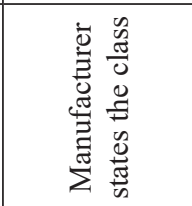 & I \\
\hline 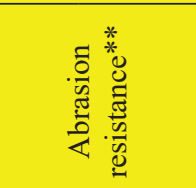 & 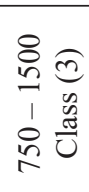 & 1 & 1 & 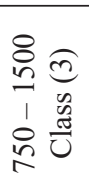 & 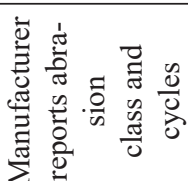 & 1 \\
\hline 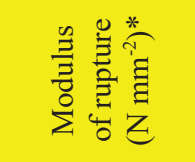 & m & 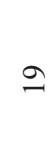 & $\underset{+}{\stackrel{+}{\Xi}}$ & ते & $\begin{array}{l}\text { ㄱ } \\
\dot{\Xi}\end{array}$ & $\begin{array}{l}\simeq \\
\dot{\Xi} \\
\dot{\Xi}\end{array}$ \\
\hline 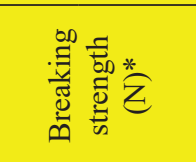 & : & $\bar{\nabla}$ & I & $\hat{\tilde{\Xi}}$ & $\begin{array}{l}8 \\
\varrho \\
\dot{\Xi}\end{array}$ & $\begin{array}{l}8 \\
8 \\
\dot{\Xi}\end{array}$ \\
\hline 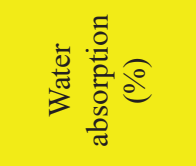 & in & $\stackrel{n}{\mathfrak{I}}$ & $\stackrel{0}{ \pm}$ & $\vec{m}$ & 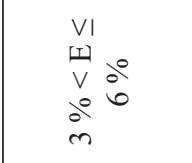 & $\begin{array}{l}\stackrel{0}{0} \\
\stackrel{0}{\wedge} \\
\stackrel{1}{1}\end{array}$ \\
\hline 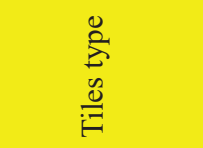 & 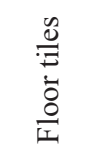 & 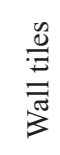 & 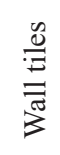 & 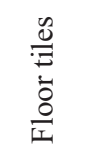 & $\begin{array}{l}\stackrel{0}{0} \\
\stackrel{0}{0} \\
\frac{0}{1}\end{array}$ & $\frac{\mathscr{0}}{\stackrel{0}{\Xi}}$ \\
\hline & \multicolumn{2}{|c|}{ 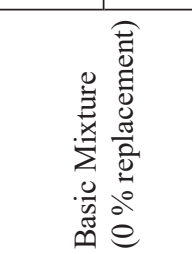 } & 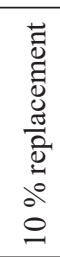 & 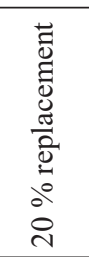 & \multicolumn{2}{|l|}{ 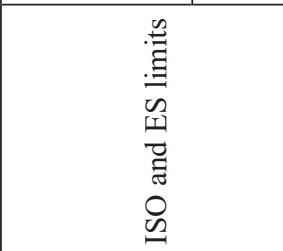 } \\
\hline
\end{tabular}

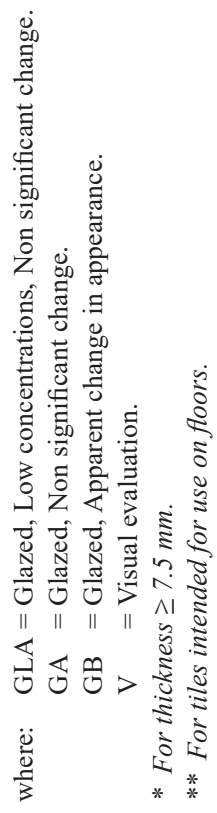


$3 \%<\mathrm{E} \leq 6 \%$ ), and up to $10 \%$ sludge for wall tiles fired at $1160{ }^{\circ} \mathrm{C}$ (for water absorption; $\mathrm{E}>10 \%$ ). The use of waste sludge as addition to ceramic tiles offers economic and environmental advantages as it makes use of a polluting waste.

\section{REFERENCES}

1. Wattanasiriwech D., Saiton A., Wattanasiriwech S. (2009): Paving blocks from ceramic tile production waste. Journal of Cleaner Production, 17 (18), 1663-1668. doi: 10.1016/j. jclepro.2009.08.008

2. Tozsin G., Oztas T., Arol A.I., Kalkan E., Duyar O. (2014): The effects of marble wastes on soil properties and hazelnut yield. Journal of Cleaner Production, 81, 146-149. doi: 10.1016/j.jclepro.2014.06.009

3. Gonzalez-Benito J., Gonzalez-Benito Ó. (2006): A review of determinant factors of environmental proactivity. Business Strategy and the Environment, 15 (2), 87-102. doi: $10.1002 /$ bse. 450

4. Tabak Y., Kara M., Günay E., Yilmaz Ş. (2012): Ceramic tile waste as a waste management solution for concrete. In: Proceedings of CRETE 2012 - $3^{\text {rd }}$ International Conference on Industrial and Hazardous Waste Management, Chania, Greece, pp. 1-8.

5. Awoyera P.O., Ndambuki J.M., Akinmusuru J.O., Omole D.O. (2016): Characterization of ceramic waste aggregate concrete. HBRC Journal, Article in press. doi: 10.1016/j. hbrcj.2016.11.003

6. Shruthi H.G., Prasad M.E.G., Taj S., Pasha S.R. (2016): Reuse of ceramic waste as aggregate in concrete. International Research Journal of Engineering and Technology (IRJET), 3 (7), 115-119.

7. Manfredini T., Marzola G., Nunziello S., Pellacani G.C., Pozzi P., Tubertini O. (1991): The recycling of ceramic sludges in the production process: An option for ceramic tile factories to reach zero pollution. Environmental Technology, 12 (10), 927-934. doi: 10.1080/09593339109385088

8. Roushdy M.H., Amin Sh.K., Ahmed M.M., Abadir M.F. (2014): Reuse of the product obtained on grinding kiln rollers in the manufacture of ceramic wall tiles. Ceramics Technical, 38, 60-66.

9. ASTM D 422 / 1963 (Reapproved 2007): Method for particle-size analysis of soils. ASTM Annual Book, U.S.A., 4 (8) (2016).

10. Micromeritics Instrument Corporation (2012). Density and Porosity, retrieved from:http://micrx.com/repository/files/ Density_and_Porosity_Definition.pdf.

11. ASTM B 311 / 2017: Standard test method for density of powder metallurgy (pm) materials containing less than two percent porosity. ASTM Annual Book, U.S.A., 2 (5) (2017).

12. Abadir M.F., Ibrahim O.A., Sersy E.H.H. (2004): A new proposed method for the estimation of the plasticity of clay Pastes. Silicates Industrials, 69 (9), 55-60.

13. De-Andrade F.A., Al-Qureishi H.A., Hotza D. (2010): Measuring and modeling the plasticity of clays. Materials Research, 13 (3), 395-399. doi: 10.1590/S151614392010000300019

14. ASTM C 326/2009 (Reapproved 2014): Standard test method for drying and firing shrinkages of ceramic whiteware clays. ASTM Annual Book, U.S.A., 15 (2) (2017).

15. ASTM C 373/2017: Standard test methods for determination of water absorption and associated properties by vacuum method for pressed ceramic tiles and glass tiles and boil method for extruded ceramic tiles and non-tile fired ceramic white-ware products. ASTM Annual Book, U.S.A., 15 (2) (2017).

16. ISO 10545-4/2014: Ceramic tiles - Part 4: Determination of modulus of rupture and breaking strength. International Organization for Standardization (ISO), Geneva, 1-16.

17. ISO 13006/2012: Ceramic Tiles-Definitions, classification, characteristics and marking, Annex $\mathrm{K}$ and L. International Organization for Standardization (ISO), Geneva, 38-43.

18. ES 3168-2/2015: Ceramic tiles, Part 2: Dry pressed ceramic tiles", Egyptian Organization for Standardization and Quality (EOS), Cairo, Egypt, 1-34.

19. McCabe W.L., Smith J.C., Harriott P. (2005): Unit Operations of Chemical Engineering. $7^{\text {th }}$ edition, McGraw-Hill, New York.

20. Kingery W.D., Bowen H.K., Uhlmann D.R. (1976). Introduction to Ceramics. $2^{\text {nd }}$ edition, John Wiley and Sons, New York, p. 9. 